D) \begin{tabular}{l|l} 
Department for Business \\
Innovation \& Skills
\end{tabular}

Implementing the New Approach to ESOL

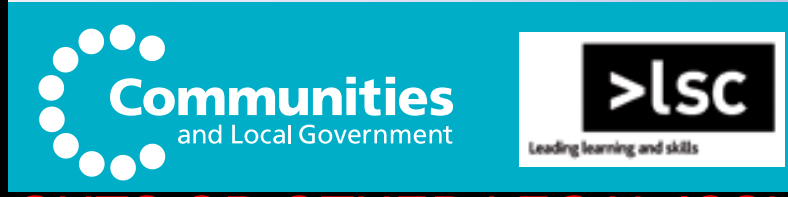

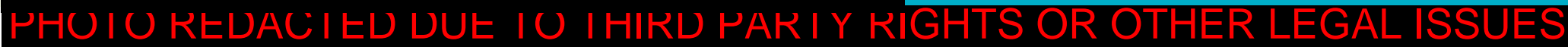




\section{Ministerial Foreword}

A New Approach to English for Speakers of Other Languages (ESOL) was published in May this year. It set out how we intend to work with local authorities, the Learning and Skills Council (LSC) and others to ensure that ESOL could play a more effective role in supporting community cohesion.

Although we know that ESOL is only one factor in improving community cohesion, it is a very important factor. Acquiring language skills is vital to someone who wants to settle here, to play a full part in society, look after and bring up a family, get a job and progress.

Encouraging and supporting community cohesion and integration is about helping people who come to Britain to help themselves. In recent years we have invested around $£ 300$ million a year in ESOL. That is a huge amount of money but the resources are finite. We need to be sure that those identified as local priority groups are supported to come forward to take up the offer.

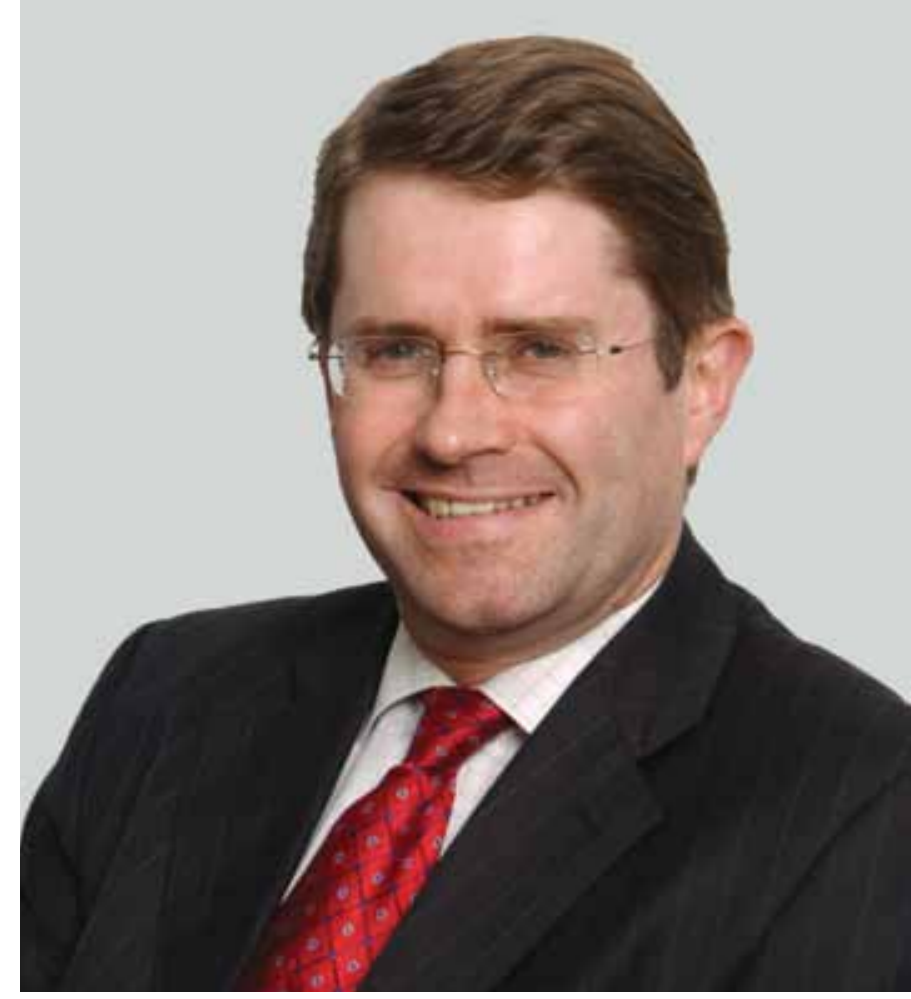

Since May, 31 pathfinder local authorities and their partners have been developing the new approach. To take this forward their experiences have been captured to support national roll-out. This is the starting point. This is an interactive process that we look to develop with you over the coming months.

When John Denham and Hazel Blears wrote to local authority chief executives in May, outlining the new approach and the role we wanted local authorities to play, we were in no doubt that we were setting local authorities - particularly the pathfinders a daunting task. We were asking them to work with us on identifying priority groups, creating action plans which would inform and drive provision in a particular place. And we were asking them to do it in a few months.

This document shows how magnificently the pathfinders local authorities rose to that challenge. It contains examples from how they got started, their advice on creating action plans and in how the new approach can usefully contribute to improving 
performance against national indicators and local area agreements. It will form the centrepiece of a series of regional workshops which will bring together local authorities pathfinders and non pathfinders, the LSC and others - to help us move forward and introduce the new approach across England.

I am very grateful to local authorities for becoming involved in this work. It has been an excellent example of partnership working in a policy area which is of huge interest across Government. I believe the experience of the pathfinders set out in this document provides a vital source of help for all local authorities and their partners. This will help ensure that our investment in ESOL is appropriately targeted locally, supporting priorities such as the settlement of those committed to living in the UK and increasing employability skills.
I look forward to hearing more about how the new approach develops. This is a policy we are determined to see work and this guide shows that, thanks to the enthusiasm and support of our partners, it has got off to an excellent start.

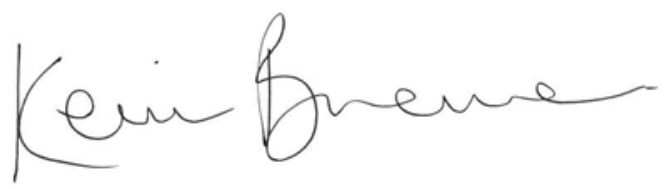

Kevin Brennan

Minister for Further Education, Skills, Apprenticeships and Consumer Affairs 


\section{Introduction}

A New Approach to English for Speakers of Other Languages (ESOL) was published in May of this year. Thirty-one local authorities began 'fast-tracking' this new approach immediately, and this document shares their experience to help other local authorities and their partners start implementation from September 2009.
It is particularly pertinent to ESOL providers who will be key in ensuring the locally prioritised learners are attracted to their ESOL provision and progress to maximise their potential.

The document is supported by a range of tools and information on how to implement the new approach which can be found at: http://www.lsc.gov.uk/whatwedo/ adultlearner/esol.htm

"everyone agrees with the concept - it's difficult to argue against the new approach"

London Borough of Lambeth 


\section{Contents}

1: Implementing the new approach to ESOL including background and the changing skills context, feedback from the pathfinders and funding

What is the new approach? 6

$\begin{array}{ll}\text { Who does what in the changing skills landscape? } & 7\end{array}$

What local authorities now need to do? $\quad 8$

Feedback from the pathfinders $\quad 8$

What help and additional information is available? $\quad 9$

2: The process and timelines for producing your local area

ESOL action plan and measuring our success 10

$\begin{array}{ll}\text { Getting started within the local authority } & 10\end{array}$

High level process and timelines for producing your Local Area ESOL Action Plan

Getting more information to get started $\quad 23$

3: Annexes $\quad 24$

A - National indicators supported through the new approach $\quad 24$

B - LSC/ SFA ESOL funding information for local authorities $\quad 25$

$\mathrm{C}$ - Roles and responsibilities $\quad 26$

D - LSIS support for providers $\quad 28$

E - Checklist of characteristics of possible priorities $\quad 29$

F - Action plan template $\quad 34$

G - Draft self-assessment template $\quad 38$ 


\section{Implementing the new approach to ESOL}

1.1 In May 2009 the former Department of Innovation, Universities and Skills (DIUS) with support from Communities and Local Government (CLG) published A New Approach to English for Speakers of Other Languages (ESOL). This is the Government's response to the consultation on ESOL in 2008 which looked at focusing English language provision on community cohesion. The overwhelming response was in favour of this focus and from the feedback received the Department, now the Department for Business, Innovation and Skills (BIS), developed its new approach.

\section{What is the new approach?}

1.2 In summary, the new approach aims to prioritise ESOL funding to those who form part of the many settled communities in England and migrants who are committed to staying in the UK. In prioritising these groups, the Government aims to localise the way ESOL budgets and support services are allocated in order to bring about local solutions to local needs. In turn, this should improve community cohesion and social integration alongside the economic vibrancy of a local area. It should also support individuals to achieve their goals for employment, supporting their families and becoming more involved in their local and wider communities. 
1.3 The key elements of the new approach are:

- to shift the mix and balance of provision and services towards locally identified priority ESOL learners;

- to allow local authorities, working with partners, more say over who has priority for ESOL funding and to align ESOL as far as possible with other local priorities and services; and

- to support providers who are already working on this agenda to make change, and bring providers not fully engaged on-board.

1.4 It is intended that the new approach builds on and is embedded within local authority wider priority setting activities; for example, Local Area Agreements, Multi Area Agreements and National Indicator discussions. Pathfinders have identified a range of the National Indicators the new approach can support which are listed in Annex A.

1.5 Investment in ESOL is already substantial and, therefore, there is no additional funding available for implementing the new approach. Local co-ordination and prioritisation of funds is expected to lead to better use of the available public funding, whilst encouraging learners and employers who can afford to make a contribution to do so. Partners should, therefore, consider all local funding that is local authority, LSC and other local funding sources - to produce a coordinated approach to funding the services and provision required to ensure locally identified priority groups can access ESOL provision. In addition, local authorities may be able to lever in support/in kind activities from existing services, such as marketing activities and advice through local authority funded services. A list of possible support/ in kind activities and non-LSC funding sources that can support the new approach can be found at http://www.lsc.gov.uk/ whatwedo/adultlearner/esol.htm.

1.6 A summary of the key aspects of FE ESOL funding is set out in Annex B.

\section{Who does what in the changing skills landscape?}

1.7 Respondents to the ESOL consultation saw that the key to the success of the policy in supporting community cohesion through ESOL is for priorities to be identified at the local level. The new approach recognises that the most effective way to achieve this is for local authorities to take the lead in identifying these priorities and sets out how, working with local strategic partners, they should influence the support services and ESOL provision in their area. The new approach aims to give local authorities the opportunity to highlight those priorities so they can receive the support and funding required to engage them. They will be undertaking this role with support from the Learning and Skills Council (LSC), and subsequently the Skills Funding Agency, and their local strategic partners, including local ESOL providers, Jobcentre Plus and the Third Sector.

1.8 The wider skills landscape is also changing considerably over the coming months. As part of the Machinery of Government changes announced in June 2007, the Skills Funding Agency (SFA) and 
Young People's Learning Agency (YPLA) will take over from the LSC to carry forward the responsibility for funding FE colleges and other providers in England from April 2010. ESOL, funded from the Skills for Life budget, will be transferred to the SFA. At regional level the Regional Development Agencies (RDA) will take up their newly enhanced strategic skills role, and Government Offices (GOs) within their Local Area Agreement responsibilities, will ensure the approach fits within local and regional priorities. We will ensure that the new approach to ESOL continues to work alongside these changes to the skills landscape.

\subsection{The roles and responsibilities of key} partners involved are set out in Annex C.

\section{What local authorities now need to do?}

1.10 The Government is looking for all local authorities to begin work in September 2009 in identifying, with their local partners, their priority groups and drawing together a plan of action to reach these potential learners. Over the past few months 31 pathfinder local authorities have begun to implement the new approach and their experiences have been captured in this publication to support roll-out across all local authorities.
1.11 The following sections set out the process and actions required to implement the new approach with a series of case studies. This must be seen as a starting point as time has been short. We will continue to share the lessons learnt over the coming year with a view to embedding this new approach as quickly as possible into day to day partnership activities.

\section{Feedback from pathfinder local authorities}

1.12 We have worked closely with the pathfinders on an ongoing basis since they began implementing the new approach in May and the proposals in this document build on their experience. In addition, all local authority pathfinders were formally invited to feed back progress and issues on the implementation of the new approach via a short questionnaire.

1.13 Significantly, from those respondents who have made greatest progress there was a higher incidence of activity in the following areas:

- they have identified that contributing to success against local indicators is critical;

- they have made contact with more departments across the local authority; 
- they have or are sharing information about the new approach with the Local Strategic Partnership and plan to integrate this strategy within the Local Area Agreement;

- they have identified key data sources;

- they have an identified lead for taking forward an ESOL action plan;

- there is an existing forum that will take responsibility for the ESOL action plan;

- they had more engagement with a variety of external stakeholders; and

- they have already begun to discuss the new approach with local ESOL providers.

\section{What help and additional information is available?}

1.14 This document aims to provide a useful guide for local authorities and their partners in implementing the new approach. Section 2 sets out a suggested set of actions to follow, and the annexes includes a range of help and additional information for the implementation of the new approach.

1.15 In addition to this, updates and further information will be posted on the LSC website as implementation goes forward. The site can be found at http://www.Isc.gov. uk/whatwedo/adultlearner/esol.htm

\subsection{A web-based application has also} been made available to local authorities to network with other local authorities and partners implementing the new approach and share good practice. Further details of the Huddle and how to join it can be found in paragraphs 2.36 to 2.37 .
1.17 Providers will be key to the successful implementation of the new approach. The Learning and Skills Improvement Service (LSIS), via their Provider Support Programme are offering a range of help to ESOL providers. The support available is set out in Annex D.

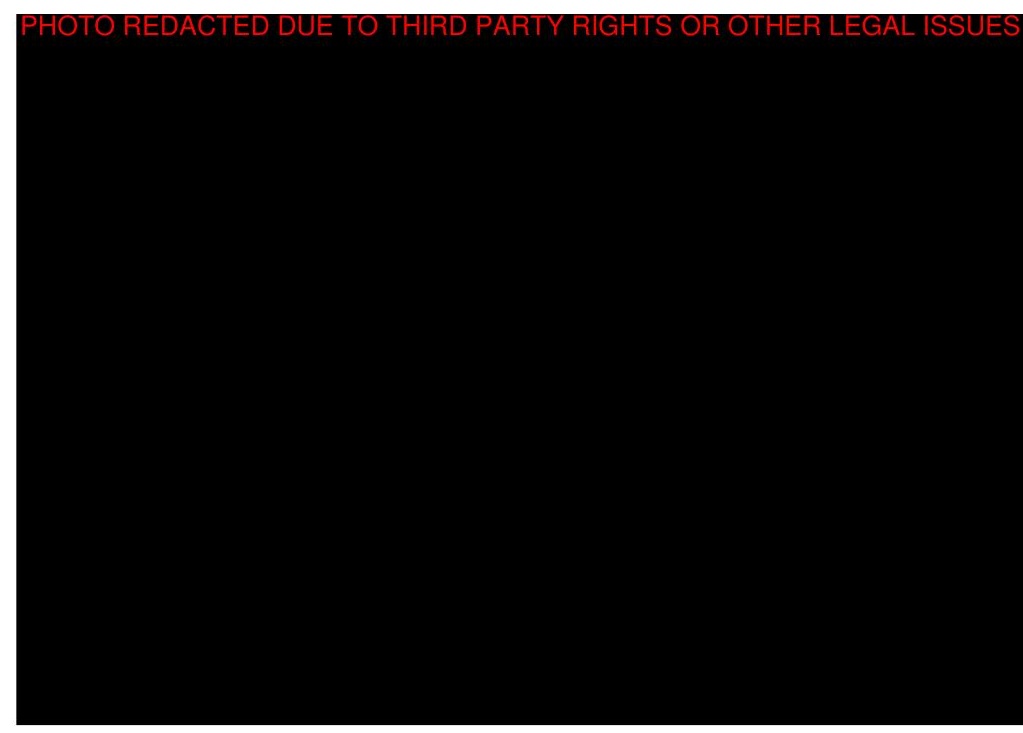




\section{The process and timelines for producing Local Area ESOL Action Plans}

2.1 Based on feedback from the pathfinders, this section sets out the intended process local authorities are recommended to follow. There are examples of how pathfinder local authorities have already worked through certain aspects of the new approach. Their experience and comments have provided valuable insight and development of a process. We will continue to work with the pathfinder local authorities and share their experiences.

\section{Getting started within the local authority}

2.2 To begin work local authorities need to consider where the leadership role will sit within their own local authority. In pathfinder local authorities, this role has been taken up by a range of teams from community cohesion, skills and employment, economic development and adult learning teams. Some local authorities decided to deliberately site this work outside of their own adult learning team due to concerns over issues of transparency and the need to ensure other local authority departments engage with the agenda.

Recognising the importance of English language learning in improving community cohesion, Leeds and

Bradford authorities have placed importance on getting the strategic leadership within the departments responsible for social cohesion and economic development involved and contributing to this work.

2.3 Cross local authority departmental working was identified as key by the majority of pathfinder local authorities and they noted the powerful effect of gaining buy-in from other departments which in some cases has led to the release of further funding for ESOL services and provision. 
London Borough of Camden reports high interest for the new approach from their Regeneration team and welcome the government prioritisation of community cohesion as a corollary to improving skills and employment. The need for ESOL in the borough has been recognised at councillor level for whom this became a reality whilst canvassing door-to-door in the recent local elections.

Slough local authority recognises that English language issues cut across all of its services. They are planning a comprehensive review of the council's priorities and strategies to ensure that ESOL prioritisation has a sound basis within the Local Area Agreement.

In Peterborough extra police have been seconded into the city to support the violent extremism initiative, and have been surprised at the scale of ESOL need. This cross departmental working could also allow the release of additional funds to support more ESOL provision.

Manchester City Council is working closely with their Housing Department which has identified areas where community integration, manifested through isolation and hate crime, is an issue. As part of the new approach action plan, funding has been identified for local providers (both the local authorities Adult Education Service and local college) to set up 'Classes 2 Clubs' - an approach which has worked well before to engage learners. Using a tutor together with volunteers and mentors, semi-autonomous learning groups are developed that provide informal language learning opportunities. Front line staff within registered social housing will receive briefings to support this activity. This builds on training which they are already receiving through the Adult Advancement prototypes, signposting people to learning and employment opportunities.

Manchester City Council has used the New Approach to look more widely at how funding can support community cohesion. It is working with the Adult Learning Service to target LSC Personal and Community Development Learning (PCDL) funding to deprived neighbourhoods inclusive of all residents but with embedded ESOL.

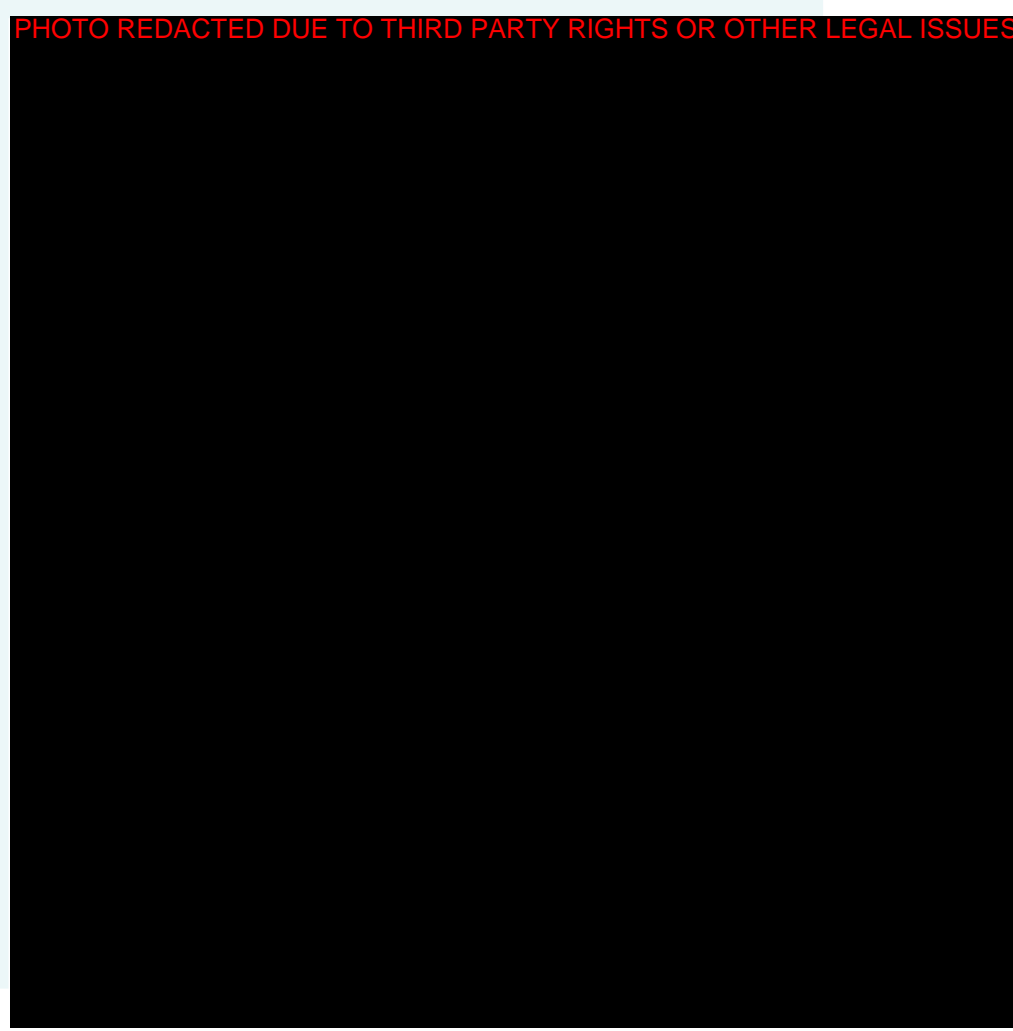


High level process and timelines

2.4 The new approach has 4 over-arching steps:

\section{STEP 1 \\ Assessing local area \\ ESOL need}

\section{STEP 4 \\ Review the local ESOL action plan and return a short self assessment capturing impact to date \\ June each year}

\author{
STEP 3 \\ Agree a Local Area \\ ESOL Action Plan \\ September each year \\ (End of December for local \\ authorities starting in \\ September 2009)
}


Birmingham local authority, following the national survey undertaken in 2003 by the then Department for Education and Skills (DfES) undertook an area wide needs survey covering ESOL.

From an analysis of local authority strategic priorities they have been able to identify the key neighbourhoods within Birmingham which have persistent concentration of ESOL needs with strong connections to community cohesion and worklessness.

\section{London Borough of Ealing has} developed a database of all local community groups from which they will be able to draw support to help guide their planning.

\subsection{Pathfinders also reviewed existing} provision to see who was currently accessing ESOL learning in their local area by working with colleges and providers, libraries, Jobcentre Plus and the Voluntary and Community Sector. Lambeth Council, for example, are using provider enrolment data, local demographics and schools data, along with data from interpreter services usage. They also found good reliable data from hospitals, the police and prison service.

Bristol City Council has identified the information that it needs from all local providers regarding their current $\mathrm{ESOL}$ provision to see who is currently accessing provision and what that provision looks like. They have drawn up templates to collect the information which LSC funded providers have agreed to complete.
2.10 To support this, a list of possible data sources has been compiled at: http:// readingroom.Isc.gov.uk/Isc/National/natusefuldatasourcesfinal-aug09.doc and the LSC Data Service has published a suite of ILR data at: http://www.lsc.gov.uk/ whatwedo/adultlearner/esol.htm broken down to individual local authority level. This data provides a breakdown on those currently taking up ESOL provision.

\subsection{Once a clearer picture is established} on where need is and who is currently accessing $\mathrm{ESOL}$, it is then easier to identify those in need but not yet accessing ESOL. This important data analysis will provide the basis of the rationale for identifying and agreeing the priority groups.

\section{STEP 2 Working with partners to identify local ESOL priority groups}

\section{Working with partners}

2.12 Local authorities should consider who to invite to work with them in identifying the gaps in provision and currently excluded groups. Some areas may already have an established group of local strategic partners who regularly meet to discuss ESOL. Some areas may not have an ESOL group, but may have groups of the right partners meeting on other issues into which ESOL could be added. And some areas may not have any appropriate existing group and will have to establish a group of relevant local strategic partners to support them. 
Bristol City Council, from having no existing partnership or ESOL forum, has engaged senior buy-in from the following departments and groups to form an ESOL Working Group: Education Department (Equalities team), extended schools partnership, LSC, Adult Social Care, Community Cohesion team, Economic Regeneration, Adult Public Health (NHS), three voluntary organisations representing broad groups of the community, Jobcentre Plus and two bilingual learning champions employed to support this work. Their first meeting will be early September and they are committed to meeting monthly up to December with responsibility for developing the action plan. They have a separate providers group which will also meet regularly to review provision.

The Newcastle area did not have an existing local group that met to discuss ESOL and the Newcastle local authority is now forming a new partnership with a view to include colleges, Voluntary and Community Sector (VCS), Jobcentre Plus (JCP), LSC, representatives from council services (children's, social cohesion, cultural), refugee groups, Newcastle Futures, and the North East Migration partnership.

To begin to get buy-in the Head of Culture, Libraries and Lifelong Learning and LSC Skills Development Director met with the Assistant Principal of Newcastle College. Agreement was reached to the principles on how they would proceed and the college is already planning to review provision and how it can support the local authority.
In Birmingham, the Core Skills

Partnership led by the local authority, a group that has been overseeing skills provision and in particular basic skills for over 10 years, has already met together three times since the launch of the pathfinder to discuss how to move forward with their identified priority need.

Slough local authority has an existing provider forum, the ESOL Project Group, that meets regularly and will take forward the new approach. However, this will follow a very strategic approach to identifying the priority needs within the local authority and then a consultation phase. This process is being put to the local strategic partnership for endorsement by early September.

London Borough Lambeth already had a Worklessness Delivery Group, chaired by the Executive Director, that reports directly to the Local Strategic Partnership, this group will take the new approach forward.

"a positive opportunity for the council to lead on the development of a long term strategic approach to ESOL, which at present is a gap. The approach will assist us to improve the skills and life chances for those communities who remain socially excluded and in poverty"

Leeds City Council 
2.13 A list of partners that local authorities may want to consider inviting is captured below and whilst not exhaustive, this will help local authorities to get started:

- Jobcentre Plus;

- All ESOL providers;

- LSC/SFA;

- Local voluntary and community organisations;

- Probation and prison services.

\section{Identifying local ESOL priority groups}

2.14 In discussion with partners and using the analysis of local need, local areas should start to identify their priority groups. Pathfinders have started to agree a range of groups, including parents and grandparents; women in specific communities; geographical areas of a city; migrant workers; and low paid workers.
To identify their priority groups

Newcastle local authority used existing knowledge from discussions with local voluntary and community groups and internal discussions with their Education and Housing departments. They were quickly able to identify the Roma community as consistently in need of but not accessing ESOL provision. Through discussions with their Housing Department they were able to establish where these communities are based and are using Neighbourhoods, Learning and Deprived Communities (NLDC) funding to pilot engagement approaches, linked to employability. Once a new partnership has been established in September, Newcastle will be able to build on this work and consider other local priority groups. 
Birmingham City Council through local planning discussions with their ESOL partners have identified priority neighbourhoods, target communities and an indication of learner language levels:

- 18 priority neighbourhoods - the priority worklessness neighbourhoods that have large number of people with English not as their first language.

- Indicative language levels ranging from pre-entry moving to entry level 1 , entry level 3 moving to level 1

- Individuals from Bangladesh, Pakistani, Somali and African-Caribbean settled communities who are currently not engaged

Peterborough has identified 2 priority groups - women in settled communities and migrant workers (predominantly new arrivals). These groups were identified through a survey of existing provision carried out across Peterborough which was then matched to their local knowledge of need (identified through work done to support National Indicator 13).

Four local authorities, Derby and London Boroughs of Camden, Lambeth and Hounslow have worked with their local schools teams and family learning departments who have identified the ESOL needs for parents of secondary school children which, if met, will impact positively on their children's learning. In Camden this is against a background of a huge population churn each year. Schools report high annual turnover of pupils in schools (in some cases 50\%) which is indicative of adult movement in and out of the borough and will need to be factored into an ESOL action plan

London Borough Hounslow had already received positive responses to working with the local Ghurkha community before the new approach. Identified through the local councillors, as an example of engagement with a section of the community which had previously been isolated from the wider community because of the lack of English language skills it provides a model for the new approach.

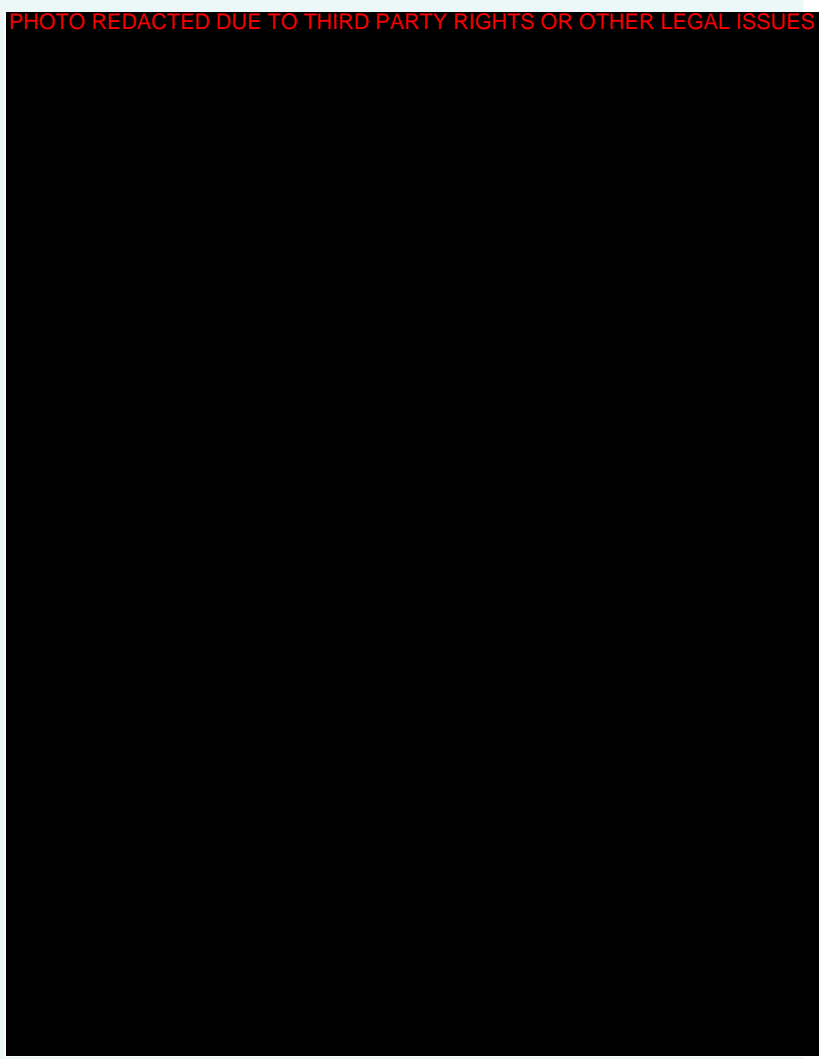


2.15 To assist with agreeing priority groups the government has set out their national priorities as those who:

- have poor or no English language skills;

- are isolated/excluded from, and not connecting with communities outside of their own;

- are currently not accessing or are underrepresented in learning provision, or are not progressing in their learning;

- are those on the path to British citizenship who are seeking to meet the English language and knowledge requirements for settlement/permanent residence, probationary citizenship (when it is introduced), and British Citizenship;

- are refugees given protection by the UK Government.
2.16 It is not intended that locally identified priority groups will meet all of these categories, but at least they will have poor or no English language skills, and this inclusive steer enables local authorities and partners to determine their own specific groups according to local need. To further support local authorities in this activity a checklist of the characteristics of possible priority individuals can be found in Annex $\mathrm{E}$ and at: http://www.lsc.gov.uk/whatwedo/ adultlearner/esol.htm

2.17 Local authorities may wish to consider conducting a local Equality Impact Assessment as part of their action plan development and ratification. The Improvement and Development Agency for local government (IDeA), who support improvement and innovation in local government, and work with councils in developing good practice, have more information to support Equality Impact Assessments at: http://www.idea.gov.uk/ idk/core/page.do?pageld=8017247 
2.18 Having agreed on priority learner groups, local authorities and partners need to agree how to engage and reach these individuals. Questions that may help this process are':

- What services and provision are required for the groups, and which organisations are best placed to deliver them?

- Which funding stream would be best suited to supporting different aspects of the plan?

- What changes need to take place to make services and provision fit for purpose for the identified groups?

- How will services and provision join up to prevent individuals getting lost?

- What are the success measures that reflect the ambitions of key local partners and service users?

- How do these actions contribute to Local Authority Agreement priorities and targets?
STEP 3 Agree Local Area ESOL Action Plan

2.19 To help local areas set out their priority groups and capture all the actions agreed by partners a suggested template of the 'Local Area ESOL Action Plan' has been developed in conjunction with the pathfinders. The development of the action plan, which is intended to also encompass impact criteria, is at the heart of the new approach. The action plan will also help local authorities communicate in a simple and consistent way any changes required to LSC/SFA funded ESOL provision.

2.20 As a result of feedback from the pathfinders we have developed two local area ESOL action plan templates to assist you with this task - the Local Area ESOL Action Plan and an 'extended' Local Area ESOL Action Plan. 


\subsection{Local Area ESOL Action Plan -} captures the basic information that the pathfinders consider a local authority will need within an ESOL action plan to successfully implement changes to local services and provision. The action plan captures four areas of activity:

- Rationale - based on the ESOL need analysis this will set out the basis for the identification of the priorities.

- ESOL priority groups - captures the priority groups you have agreed

- Key actions required - details of the activities agreed by partners to engage potential ESOL learners from the priority groups

- Impact criteria - sets out four key areas that will help us collectively to determine the impact of the new approach at a local, regional and national level. The four key areas are:

- partnership plans to deliver a change in ESOL provision to better support the needs of identified priority groups

- partnership plans to align services and/ or lever in additional (non-LSC) funding to support ESOL learners

- partnership plans to use ESOL provision to further the community cohesion agenda in the local area

- partnership plans to use ESOL provision to improve the employability and progression of learners in the local area
2.22 The template itself is set out in Annex $F$ and an electronic version is available at http://www.lsc.gov.uk/whatwedo/ adultlearner/esol.htm

\subsection{3 'Extended' Local Area ESOL Action}

Plan - covers all the areas above plus a wider range of planning information that local authorities may find useful to capture, for example, constraints and controls, risks and issues, partnership working etc. Local authorities may use all or part and amend and add to the template according to their needs. An electronic version of the 'extended' template is available at http://www.lsc.gov.uk/whatwedo/ adultlearner/esol.htm

\section{Impact of the new approach}

2.24 The pathfinders were particularly keen to ensure that collectively there is clarity at the start of implementation on how we will determine success. Local authority feedback will help inform BIS and the SFA where further change may be required to achieve policy aims. As such, the proposed impact criteria set out above have been incorporated within the action plan template.

2.25 Clarifying the impact criteria has been challenging during the short period in which the pathfinders have been working and we will continue to develop them in light of experience and continued feedback.

2.26 It would be enormously helpful if all local authorities were able to complete, within their action plan, the impact criteria in a common format so impact can be assessed collectively across the country. The criteria are not performance measures 
of local authorities, but are intended as a means of local authorities being able to feedback how the policy is being implemented and their views (on behalf of all partners) on success. Inevitably it will take time for the full impact to be realised.

\section{Changing the Mix and Balance of Provision}

2.27 The new approach is based on local partners, including ESOL providers, working together to engage currently excluded learners. Providers, as their contribution to the partnership working, are expected to ensure the mix, balance and mode of their ESOL provision is geared towards meeting locally prioritised needs.

\subsection{Contained in the proposed action} plan template is a set of data that captures changes required to current provision. This is not asking local authorities to plan all local ESOL provision, but simply allows notes to be made on the changes required. This enables all partners to be clear about any required local changes to ESOL provision.

\subsection{The data set can also be used to} support LSC/SFA provider dialogues for the coming academic year, to ensure provision is responsive to local action plans. Ordinarily, as part of the LSC/SFA planning cycle, this information would be needed in September to inform strategic planning, however due to the tight timelines, if this data was shared with the LSC by December 2009 it could be used to inform provider dialogues during January - March 2010.

2.30 To understand the changes needed in provision and making those changes will not happen over night, and full alignment of provision against locally identified priorities will take longer than the first year but providers are expected to begin to make changes in 2010/11, and where possible in 2009/10.

\section{STEP 4 Review action plan and undertake self assessment}

2.31 To understand if the new approach is succeeding and bringing about positive local change we would ask local authorities to review their action plans each year in June and return a short self assessment to the LSC to record impact of the new approach.

2.32 The self assessment return will cover the four impact criteria at paragraph 2.21. In addition we will be asking local authorities to let us know if you consider that your ESOL action plan is being achieved overall. A copy of the draft self assessment template is at Annex G.

2.33 Having reviewed the plan and progress against the impact criteria local authorities and partners should update their plan for the next academic year.

\section{Embedding the new approach}

2.34 In order to ensure the new approach to ESOL is sustainable, it is important that it becomes embedded into existing and emerging structures and processes.

2.35 Pathfinders have noted how responsive other local authority departments have been once they realise the importance good English language skills has on a variety of local services and facilities, from health, housing, schools, unemployment, economic regeneration as well as social integration and cohesion issues. 
Birmingham local authority has, against each of the National Indicators in their Local Area Agreement (LAA), reviewed how English Language impacts on them and noted potential resulting actions and outputs. This helps to see the many ways English language impacts on the widest aspects of a local area and possible ways improved English language can help a local authority achieve in different areas. A copy of this document can be found on the ESOL Huddle website at: www.huddle.net. See paragraph 2.37 for joining instructions.

\section{Greater Manchester: from the} individual action plans being developed by each local authority a Greater Manchester ESOL action plan will be collated. Each local authority is looking to have their Deputy CEO sign their plan off and the aim is for the Greater Manchester action plan to be adopted by Association of Greater Manchester Authorities. Greater Manchester also wants to link this work to the Adult Advancement and Careers Service prototype which the 10 authorities are coordinating. Wigan in particular is keen to make this link as their existing Information, Advice and Guidance service is already well coordinated with an engagement strategy to bring learners in through informal learning.

Peterborough: had an established ESOL Operations Group which will be renamed ESOL Delivery Board and responsible to the Adult Skills and Strategy Group (ASSG) for its steer. The ESOL Delivery Board will have its action plan and priority groups reviewed and endorsed by the ASSG. The ASSG reports to the Local Strategic Partnership so in this way the ESOL action plan will underpin the Local Area Agreement.

\section{London Borough of Hounslow is}

working with the local LSC to ensure the ESOL new approach is on the Local Strategic Partnership agenda, and the LSC is leading on a presentation to the group. The LSC is also supporting partnership with the colleges. 


\section{Getting more information to get started}

2.36 Local authorities and their partners are invited to make use of the Huddle webbased application. This allows a number of activities including virtual meetings, sharing of documents and, crucially, the ability to network and share good practice in implementing the new approach. Huddle has been used by the local authority pathfinder areas and it is clear that it offers a quick, efficient way to consult and discuss emerging issues and good practices with others.
2.37 Those interested in joining the ESOL Huddle site should send their name, job title and email address to esol@bis.gsi.gov.uk to receive registration details.

2.38 The LSC/SFA will also post updates and further information on the implementation of the new approach as work goes forward. The website can be found at http://www.lsc.gov.uk/whatwedo/ adultlearner/esol.htm. Queries can be sent to a helpdesk on this site, or can be addressed to one of the LSC regional ESOL leads listed on the page.

\section{"Huddle has been used \\ by the local authority}

pathfinder areas and it is

clear that it offers a quick, efficient way to consult and discuss emerging issues and good practices with others." 


\section{Annex A \\ Local authorities noted the following national indicators can be supported through the new approach:}

\section{Stronger communities}

NI 1 - percentage of people who believe people from different backgrounds get on well together in their local area PSA 21

NI 2 - percentage of people who feel that they belong to their neighbourhood PSA 21

NI 12 - refused and deferred Houses in Multiple Occupation (HMO) license applications leading to immigration enforcement activity HO DSO

NI 13 - migrants English language skills and knowledge HO DSO

NI 14 - avoidable contact: The average number, of customer contacts per received customer request

\section{Safer communities}

NI 15 - serious violent crime rate PSA 23

NI 25 - satisfaction of different groups with the way the police and local council dealt with anti-social behaviour HO DSO

NI 26 - specialist support to victims of a serious sexual offence PSA 23

NI 27 - understanding of local concerns about anti-social behaviour and crime by the local council and police HO DSO

\section{Local economy}

NI 151 - overall employment rate PSA 8

NI 152 - working age people on out of work benefits PSA 8

NI 153 - working age people claiming out of work benefits in the worst performing neighbourhoods DWP DSO

NI 161 - learners achieving a level 1 qualification in literacy PSA 2

NI 162 - learners achieving an entry level 3 qualification in numeracy PSA 2

NI 163 - working age population qualified to at least level 2 or higher PSA 2 


\section{Annex B \\ LSC/SFA ESOL funding information for local authorities}

$1 \mathrm{It}$ is acknowledged that public funding alone cannot be expected to meet all the demand for English language learning. For this reason prioritisation of public funds must happen to allow those who can afford to pay to make a contribution and support those most in need, who show a commitment to living in the UK.

2 The LSC, and subsequently Skills Funding Agency, will remain responsible for allocating the current FE ESOL budget to providers. The new approach is not expected to affect funding levels to providers, certainly within the first year (2010/11).

3 The LSC will fund all levels of ESOL provision from pre-entry to level 2 and it is expected that around $85 \%$ per cent of ESOL provision to continue to be delivered at the lower levels.

4 The LSC will continue to fund non-approved pre-entry and a small amount of non-approved entry level provision (20\%) of entry through its Skills for Life budget in 2009/10.

5 The current fee remission rules will also continue to apply, with standard eligibility criteria for full fee remission remaining as set out in the LSC's funding guidance.

6 BIS has instructed the LSC to continue to add some funding to the discretionary Support Fund until March 2010, which supports fees for certain groups of ESOL learners. Please see the discretionary Support Guidance for more details.

$7 \mathrm{ESOL}$ providers will still be expected to provide ESOL to those learners who demand it, outside of the locally identified groups, as we expect only a proportion of the budget to be directed towards these groups. However, those learners who are not identified as part of this exercise may need to wait for a place to become available as the demand created by the new approach may cause some displacement.

8 Very little ESOL is currently delivered through Train to Gain, however LSC Employer Responsive funding can be used in supporting the new approach to ESOL where the employer is involved with local partners in reaching certain groups of learners. For example, a local area in identifying a specific group may work with employers who employ them to increase take up of ESOL. In this situation Train to Gain funds could support the new approach to ESOL. 


\section{Annex C}

\section{Roles and Responsibilities}

\section{Local Authorities}

- bring together key local partners (including ESOL providers) to identify priority groups

- with partners, identify changes to be made to provision and services to drive up demand among these groups

- with partners, ensure that all appropriate funding streams that can address the needs of the identified priority groups are considered and mobilised. This should include sources from all relevant public funds, including across local authority departments, as well as contributions from employers/individuals where appropriate

\section{Providers}

- work with local authorities and partners to ensure provision is responsive to any locally identified gaps in current provision i.e. flexible learning times and delivery locations, roll on, roll off provision, short intensive ESOL packages

- prioritise the needs of those people identified as priorities for provision and shape provision so that it meets their needs. Consider other barriers to access - for example childcare arrangements

- develop engagement strategies around any locally identified priority groups and measure success in bringing them into learning - the role of Information Advice and Guidance services will also be important in helping to point learners towards appropriate provision

- include in the engagement strategies effective and equitable partnership work with appropriate voluntary and community sector organisations

\section{The Third Sector}

- support local authorities in identifying currently excluded groups who could be helped by ESOL

- work with local authorities and providers to support outreach work and other engagement activities

\section{Jobcentre Plus}

- feed the needs of their clients into local planning discussions

- play a special role when employability or progression is identified in the local action plan

- bring expertise and data around local employment and employability issues

- maximise opportunities for ensuring seamless referrals to appropriate ESOL provision 


\section{The Learning and Skills Council / Skills Funding Agency}

- be an active partner and, where requested, influence provision through allocations and planning discussions with colleges and providers

- continue to be accountable for and allocate FE spending for ESOL

- support local authorities and partners in implementing the new approach

\section{BIS}

- oversee the policy for the new approach to ESOL 


\section{Annex D \\ The Learning and Skills Improvement Service (LSIS) Skills for Life Support Programme and the new approach to ESOL}

The Skills for Life Support Programme will support providers in implementing the new approach to ESOL and will do this in a number of ways:

\section{Run training, networking and information sessions for providers}

These events will update providers on the new approach, give providers an opportunity to consider the implications of the changing policy context for their organisation and prepare for change. The information sessions will complement the events being run by the LSC for local authorities and will report back on lessons learnt from the pathfinders and what implications these have for ESOL providers. Events will be practical and will look at ways in which providers can get started in contributing to the new approach. The development of the events will be organic and customised; the Support Programme will develop them to respond to the changes as they occur. There will be 9 events in total, one per region, with up to 30 participants per event.

\section{Support providers through the Whole Organisation Approach to Skills for Life} The Skills for Life Support Programme will offer support on the new approach to providers through the Whole Organisation Approach strand. LLU+ will brief and support Development Advisors to prepare them to include the challenges of the new approach in action plans. We will do this through the Development Advisors briefing events and through the Community of Practice (see below). We will also provide phone and email support for Development Advisors who have queries about the new approach and the implications for providers.

\section{Community of Practice on ESOL and the new approach}

The Excellence Gateway will host a community of practice for ESOL providers working towards the new approach to ESOL. This site will include the lessons learned from the pathfinders, FAOs, case studies and useful links. The content will be developed in line with the issues and requests for information arising from the training, information and networking events and in line with the developments in local authority progress towards the new approach. 


\section{Annex E \\ Checklist of characteristics of possible priorities}

Further input to the identification of local priorities, the checklist below provides a list of some of the characteristics of individuals that, typically, have skills and employment needs. There are four likely groupings:

- adults not in work, with personal, family and/or community goals as first priorities;

- adults not in work, but with work as a primary goal;

- adults in work with skills needs; and

- 14-19 year olds with skills needs (not in work and employed).

Within each of these groupings there are a number of possible sub-groups which should be considered as a starting point for discussion. 


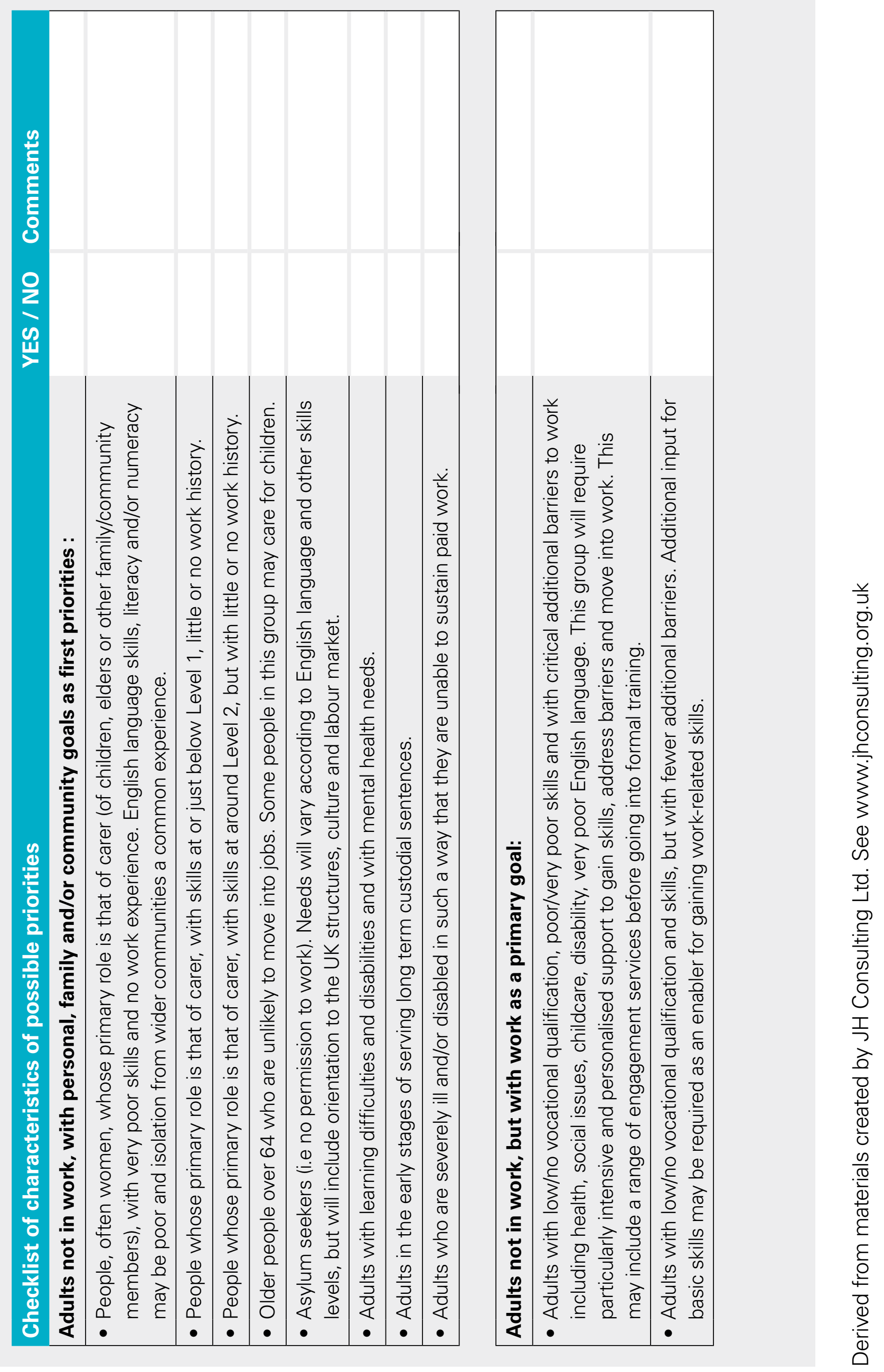


일
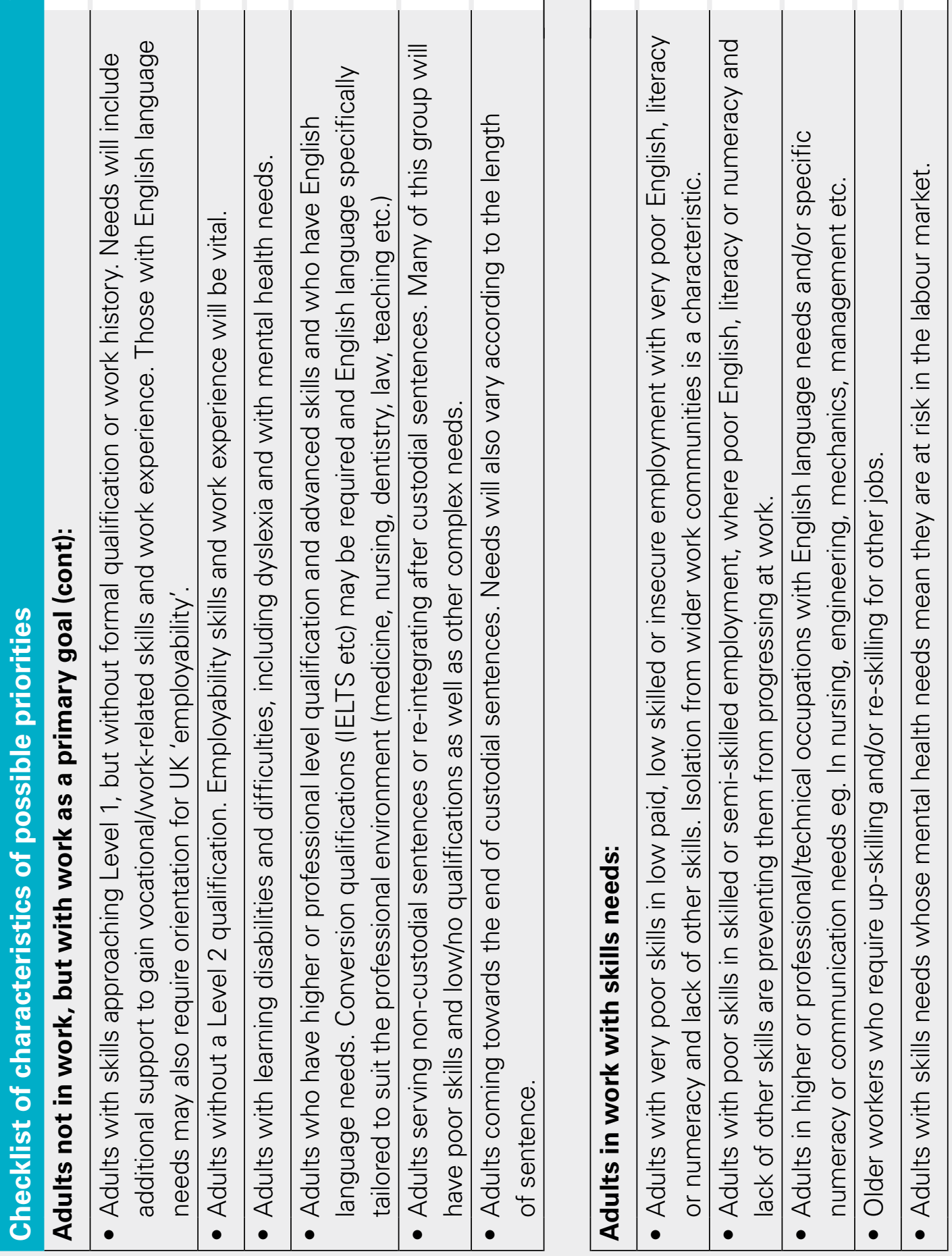

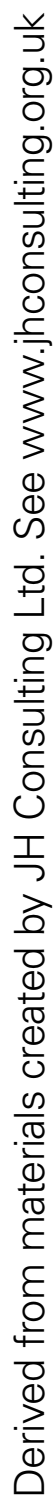


$\frac{2}{2}$

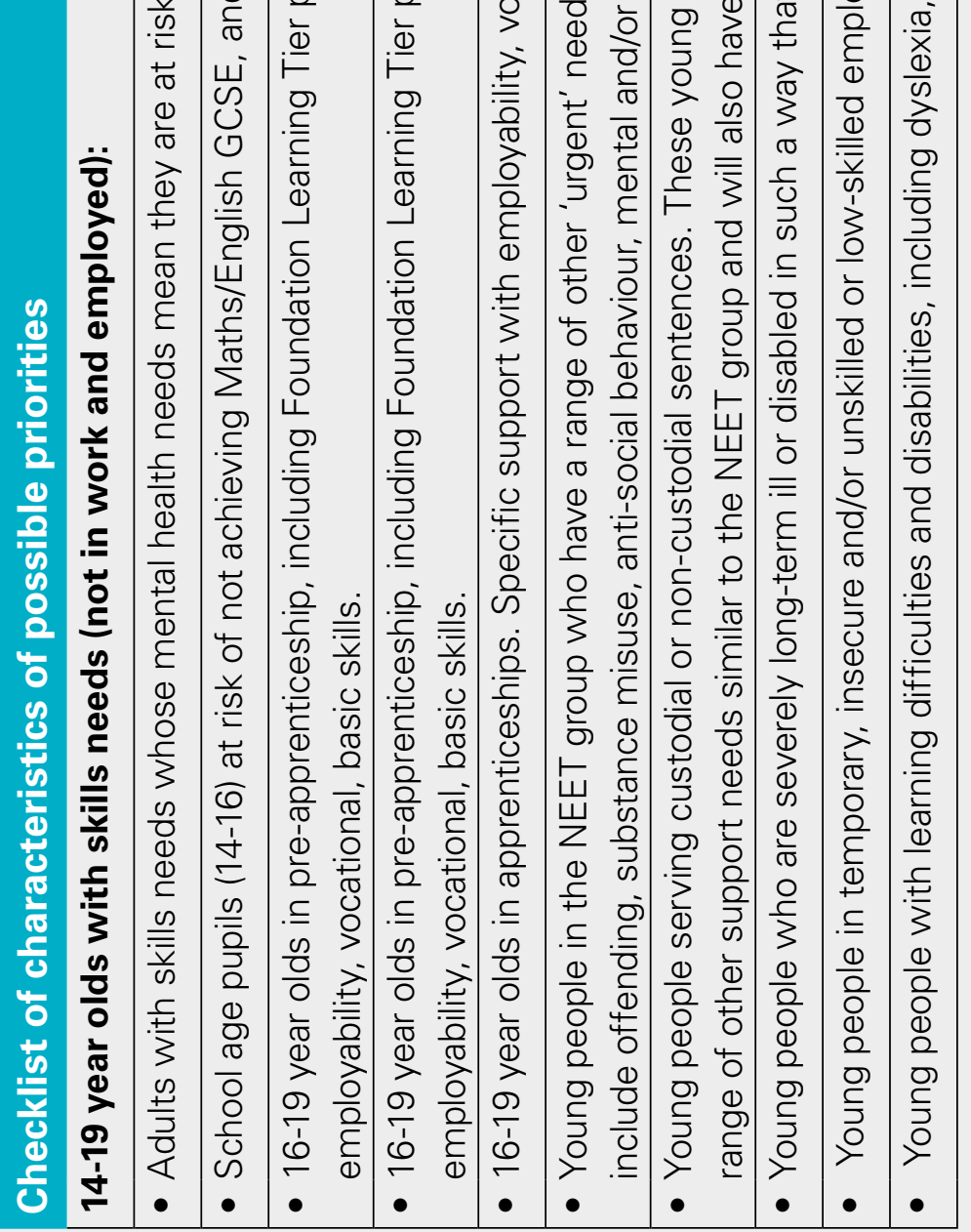




\section{Example goals of individuals with skills and employment needs}

As further input to the identification of local priority groups, the checklist below contains a broad selection of personal goals often held by individuals that have skills and employment needs. Of course, people may have more than one goal and goals will change over time as people acquire new skills and progress:

- Attending outreach and engagement activities regularly and developing soft skills associated with group work etc.

- Improving family life and/or personal effectiveness in some way

- Contributing to the life of wider communities in some way

- Volunteering

- Work experience, work placement with training or work trial

- An intermediate labour market placement/job

- A part of full time entry level job with appropriate qualification
- Qualification or units of a qualification (must be linked to a broader goal such as volunteering or a paid job)

- A full or part time job requiring Level 2 skills with further training

- A full or part time job requiring above Level 2 skills with further training leading to a qualification

- Start up business, including community businesses

- Movement into a job at a higher skills level or with better prospects in different skills sector

- Promotion to a job at a higher level 


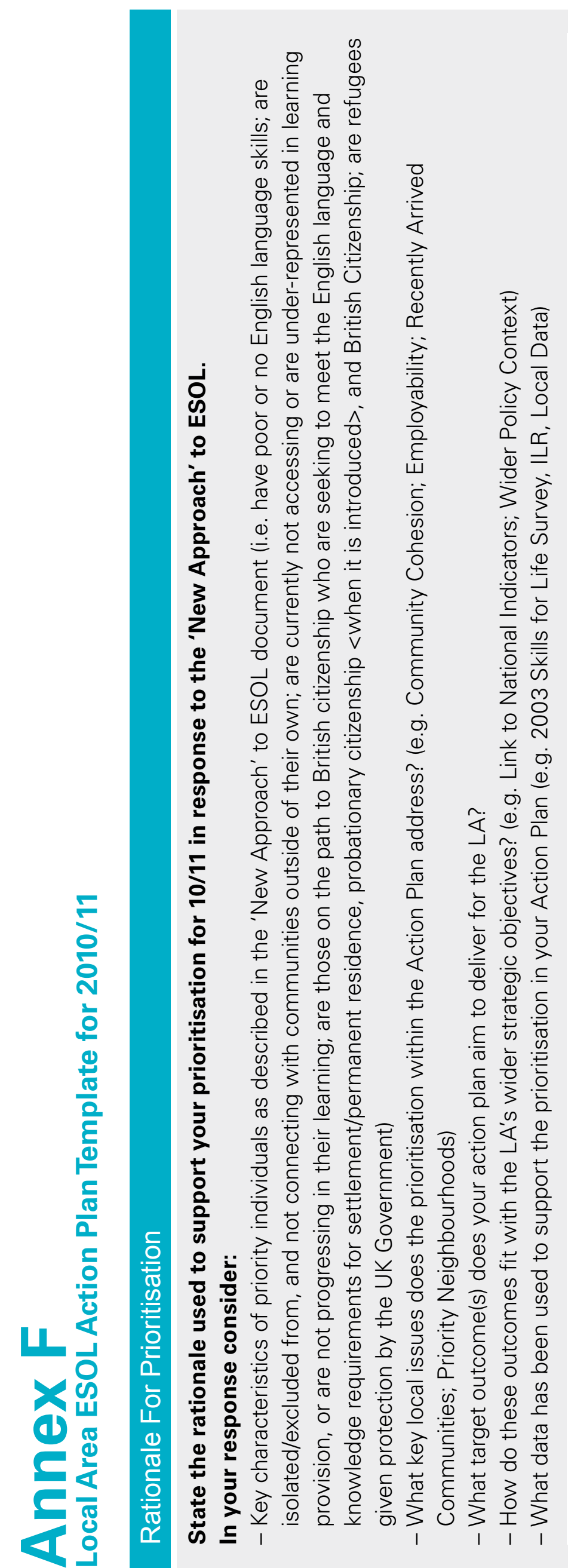

34 Implementing the New Approach to ESOL 

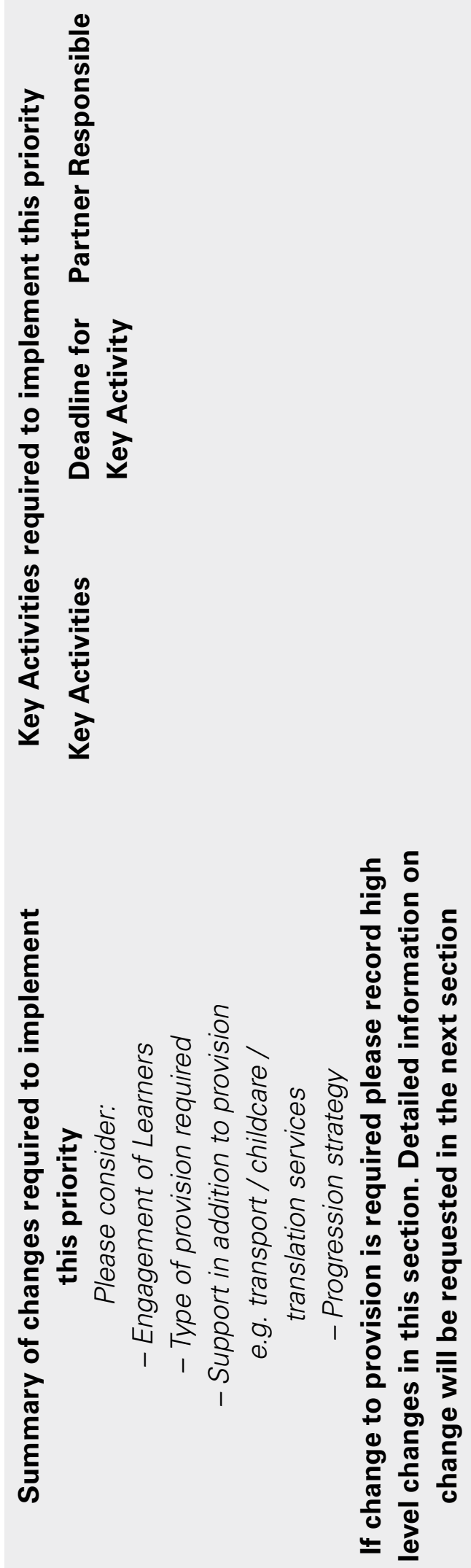

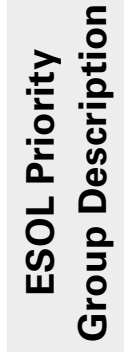




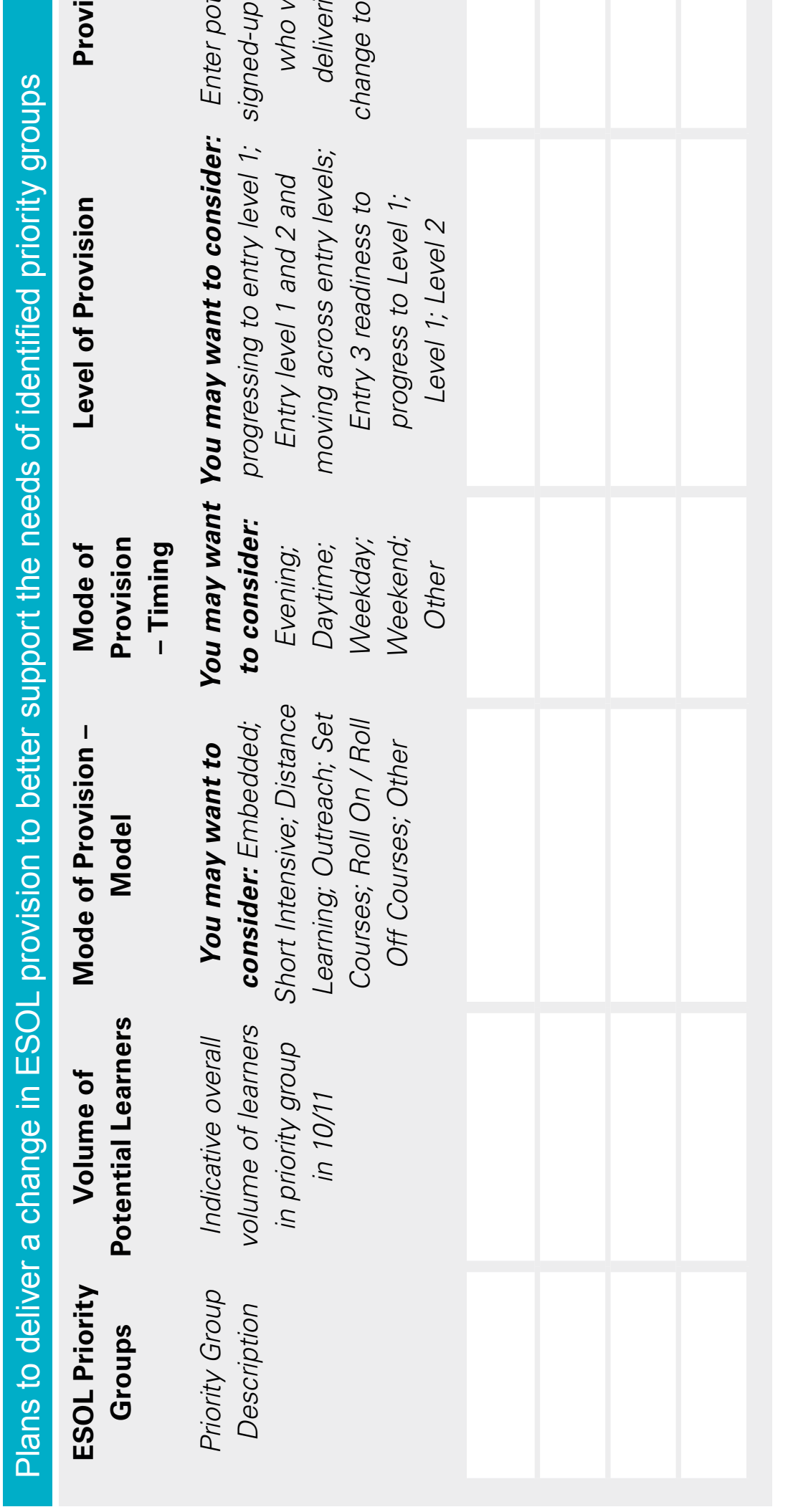

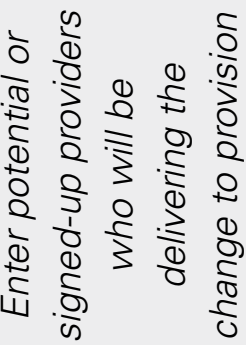
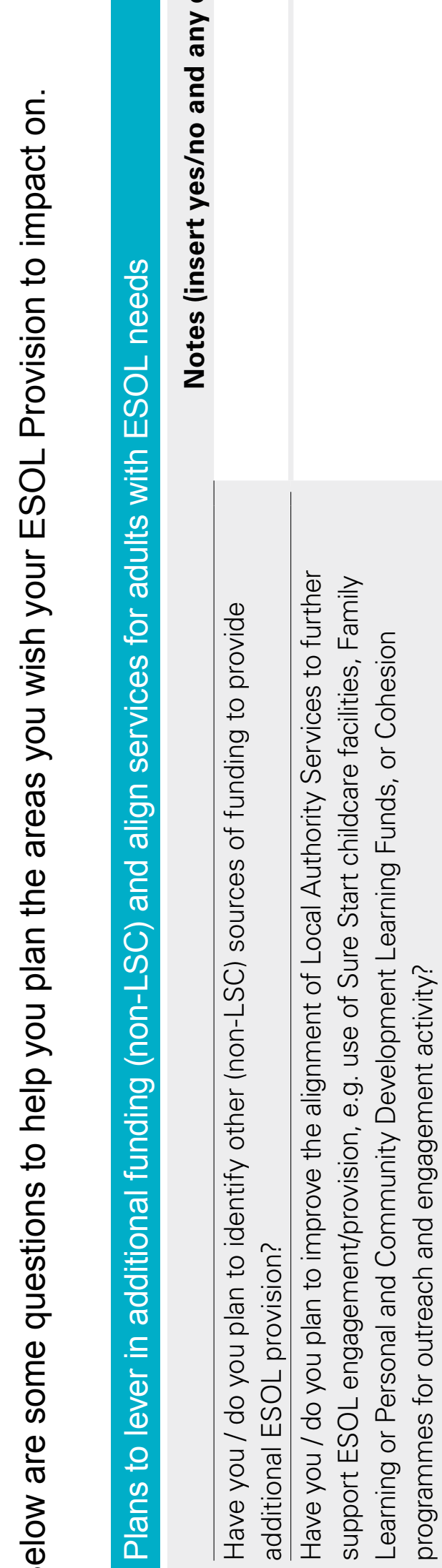

36 Implementing the New Approach to ESOL 


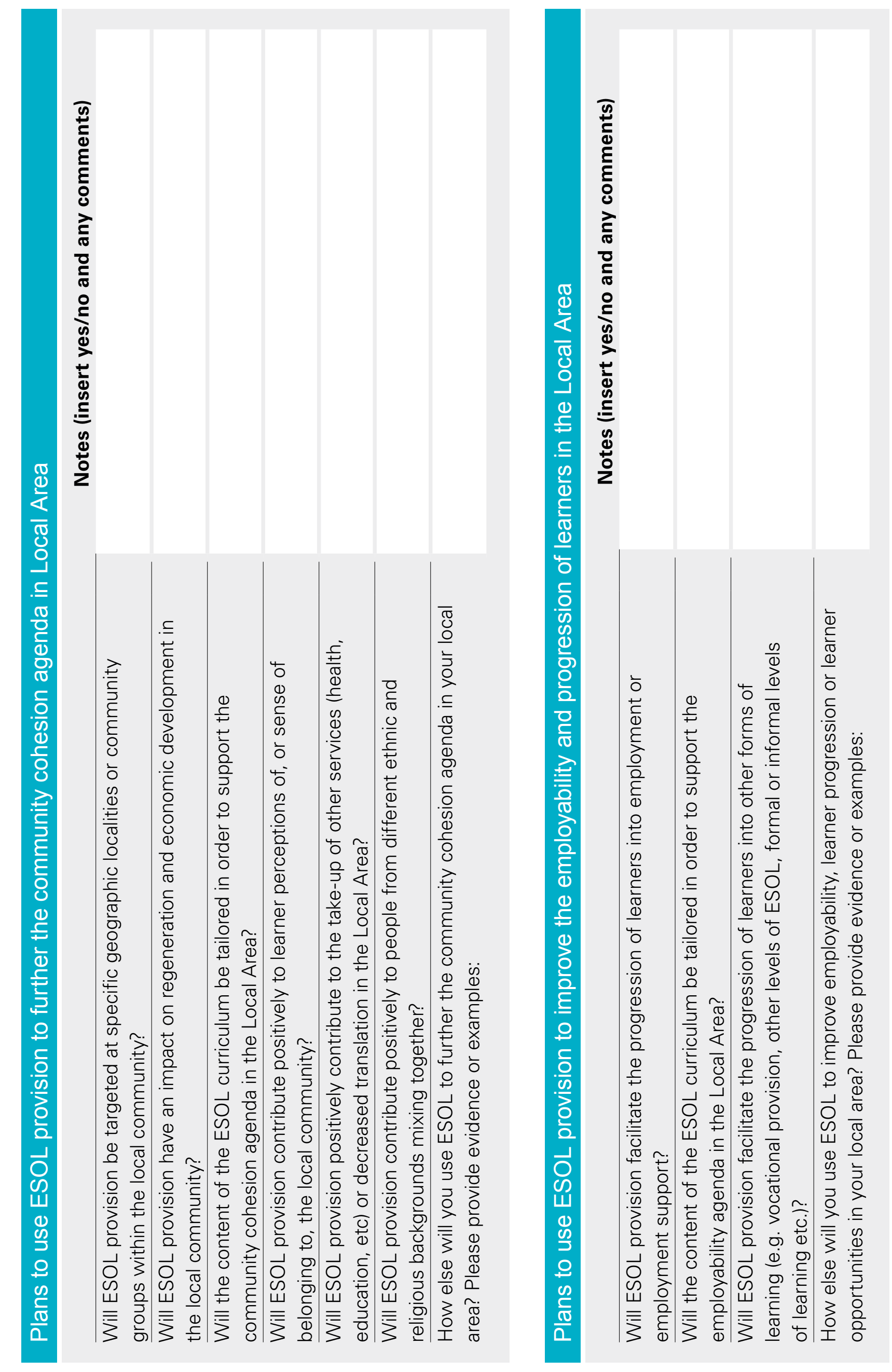




\section{Annex G}

The draft self assessment template for completion in June 2010

\begin{tabular}{|c|c|c|c|}
\hline Impact Criteria & $\begin{array}{c}\text { RAG } \\
\text { Rating }\end{array}$ & RAG definition & $\begin{array}{l}\text { Any supporting } \\
\text { information }\end{array}$ \\
\hline \multirow{3}{*}{$\begin{array}{l}\text { 1) There has been } \\
\text { a change in ESOL } \\
\text { provision to support } \\
\text { identified priorities, } \\
\text { where appropriate }\end{array}$} & Red & $\begin{array}{l}\text { Change required but no changes taking } \\
\text { or expected to take place }\end{array}$ & \\
\hline & Amber & $\begin{array}{l}\text { Change required with limited change } \\
\text { taking or expected to take place }\end{array}$ & \\
\hline & Green & $\begin{array}{l}\text { All or most planned changes taking or } \\
\text { expected to take place; or no change } \\
\text { planned as not needed }\end{array}$ & \\
\hline \multirow{3}{*}{$\begin{array}{l}\text { 2) There has been an } \\
\text { alignment of services } \\
\text { and/or a levering in of } \\
\text { additional (non-LSC) } \\
\text { funding to support } \\
\text { ESOL learners }\end{array}$} & Red & $\begin{array}{l}\text { Planned alignment and additional funding } \\
\text { has not been realised }\end{array}$ & \\
\hline & Amber & $\begin{array}{l}\text { There has been some alignment } \\
\text { of services and some additional } \\
\text { funding realised }\end{array}$ & \\
\hline & Green & $\begin{array}{l}\text { There is clear alignment of services and } \\
\text { additional funding secured to support } \\
\text { ESOL learners }\end{array}$ & \\
\hline \multirow{3}{*}{$\begin{array}{l}\text { 3) ESOL provision } \\
\text { is furthering } \\
\text { community cohesion } \\
\text { in the Local Area }\end{array}$} & Red & $\begin{array}{l}\text { No visible impact of ESOL } \\
\text { on community cohesion }\end{array}$ & \\
\hline & Amber & $\begin{array}{l}\text { Some visible impact of ESOL } \\
\text { on community cohesion }\end{array}$ & \\
\hline & Green & $\begin{array}{l}\text { Clear visible impact of ESOL } \\
\text { on community cohesion }\end{array}$ & \\
\hline \multirow{3}{*}{$\begin{array}{l}\text { 4) ESOL provision } \\
\text { is improving } \\
\text { employability and } \\
\text { progression of } \\
\text { learners in the } \\
\text { Local Area }\end{array}$} & Red & $\begin{array}{l}\text { No visible impact of ESOL on employability } \\
\text { and/or progression of learners }\end{array}$ & \\
\hline & Amber & $\begin{array}{l}\text { Some visible impact of ESOL on } \\
\text { employability and/or progression of learners }\end{array}$ & \\
\hline & Green & $\begin{array}{l}\text { Clear visible impact of ESOL on } \\
\text { employability and/or progression } \\
\text { of learners }\end{array}$ & \\
\hline \multirow{3}{*}{$\begin{array}{l}\text { 5) ESOL action plans } \\
\text { are being developed } \\
\text { and implemented }\end{array}$} & Red & No action plan being developed & \\
\hline & Amber & $\begin{array}{l}\text { Action plan in development but not } \\
\text { yet ready }\end{array}$ & \\
\hline & Green & $\begin{array}{l}\text { Action plan in place and being } \\
\text { implemented }\end{array}$ & \\
\hline
\end{tabular}

38 Implementing the New Approach to ESOL 

First published September 2009

Department for Business, Innovation and Skills www.bis.gov.uk

URN 09/1210 - Implementing the New Approach to ESOL (C) Crown Copyright 